\title{
Multiplicação de cultivares de goiabeira por miniestaquia
}

\author{
Jalille Amim Altoé $\left({ }^{1 *}\right)$; Cláudia Sales Marinho (1); Maria Isabela da Costa Terra $\left({ }^{2}\right)$; Almy Júnior \\ Cordeiro de Carvalho (') \\ (') Universidade Estadual do Norte Fluminense 'Darcy Ribeiro' (UENF/CCTA/LFIT), Av. Alberto Lamego, 2000, 28013-602 Campos \\ dos Goytacazes (RJ), Brasil. \\ (2) Universidade Federal de Lavras (UFLA/DCF), Campus Universitário, 37200-000 Lavras (MG), Brasil. \\ (*) Autor correspondente: almy@uenf.br
}

Recebido: 29/out./2010; Aceito: 14/mar./2011

\begin{abstract}
Resumo
O uso da miniestaquia para a multiplicação de cultivares de goiabeira pode permitir o estabelecimento de novos protocolos para a obtenção de mudas produzidas em condições de controle ambiental. Este trabalho foi realizado com o objetivo de avaliar a técnica de miniestaquia para multiplicação de cultivares de goiabeira. Foram instalados três experimentos em delineamento de blocos casualizados, utilizando-se quatro cultivares (Paluma, Pedro Sato, Cortibel 1 e Cortibel 6) e quatro repetições. Foram avaliados a emissão de brotações das minicepas após sucessivas coletas, a capacidade de enraizamento das miniestacas em diferentes épocas e o crescimento das mudas. As minicepas tiveram capacidade de emissão de brotações dos 49 aos 397 dias após o desponte, permitindo sete coletas de brotações. A maior porcentagem de enraizamento das miniestacas foi verificada em dezembro. Nessa época, constatou-se que as cultivares Paluma, Pedro Sato, Cortibel 1 e Cortibel 6 tiveram médias de 92\%, 75\%, 75\% e 79\% de enraizamento respectivamente. Entretanto o percentual de enraizamento das miniestacas da 'Cortibel 1' foi mais influenciado pelas épocas, sendo registrados 16,7\% e 45,8\% em novembro e em junho respectivamente. Aos 138 dias após o estaqueamento, as alturas das mudas estavam dentro dos padrões técnicos recomendados para o plantio no campo, entre 45 e $50 \mathrm{~cm}$. Com base nesses resultados, conclui-se que a miniestaquia é viável para a multiplicação dessas cultivares.
\end{abstract}

Palavras-chave: Psidium guajava, minicepas, propagação, mudas.

\section{Multiplying guava cultivars by minicutting technique}

\begin{abstract}
The use of the minicutting technique for multiplying guava tree cultivars might allow the establishment of new protocols to obtain plantlets grown under better environmental control. This study was carried out to evaluate the minicutting technique for multiplying guava tree cultivars. Three experiments were carried out in randomized block design, using four cultivars (Paluma, Pedro Sato, Cortibel 1 and Cortibel 6) and four replicates. In these experiments, the lateral shoot emission of ministumps after successive harvests, the rooting capacity of cuttings in different seasons and the growth of plantlets were evaluated. The highest percentage of cutting rooting was observed in December. By that time, the average rooting of cultivars Paluma, Pedro Sato, Cortibel 1 and Cortibel 6 was 92\%, 75\%, 75\% and 79\%, respectively. However, the rooting percentage of 'Cortibel 1' minicuttings was most influenced by the month of the year, ranging from $16.7 \%$ and in November to $45.8 \%$ in June. After 138 days from cutting establishment, the plantlet heights were within the recommended technical standards for transplanting to the field, between 45 and $50 \mathrm{~cm}$. Based on these results, it was concluded that the minicutting technique is feasible for multiplying these cultivars.
\end{abstract}

Key words: Psidium guajava, ministumps, propagation, nursery trees.

\section{INTRODUÇÃO}

A cultura da goiabeira está difundida em todas as regiôes do Brasil, em área colhida de 14.987 hectares, com produção de 297.377 toneladas, em 2009 (IвGE, 2011). A abrangência de cultivo da goiabeira ocorre em virtude de sua importância econômica, social e alimentar (Piedade Neto et al., 2003).

No Brasil, a propagação comercial da goiabeira vem sendo realizada, principalmente, por meio da estaquia herbácea em câmaras de nebulizaçáo intermitente (ZieTEMANN e RoberTo, 2007). As matrizes selecionadas para fornecimento de estacas devem ter as características da cultivar desejada, boas condições fitossanitárias, hídricas e nutricionais (Pereira e Nachtigal, 2002). As matrizes são, geralmente, mantidas no campo, o que dificulta a obtenção de propágulos de ótima qualidade e a qualquer época.

A produção de mudas da goiabeira com maior rigor no controle fitossanitário é de grande importância, uma vez que essa cultura enfrenta sérios problemas com 
doenças e pragas quarentenárias, citando-se como exemplos, a bacteriose, causada por Erwinia psidii (MARQues et al., 2007) e o nematoide das galhas, denominado Meloidogyne mayaguensis (Almeida et al., 2008).

Uma alternativa para a obtenção de mudas de melhor qualidade é manter as matrizes em ambiente protegido e utilizar substrato estéril na produção das mudas. O estabelecimento de minijardins de cultivares comerciais para o fornecimento de miniestacas poderia atender a esse propósito. A miniestaquia é uma técnica de propagação caracterizada pela coleta de brotaçóes, de plantas previamente propagadas pelo método de estaquia convencional (Alfents et al., 2004) ou por via seminífera, como fontes de propágulos vegetativos para a formação do minijardim clonal e vem sendo aplicada, comercialmente, principalmente na propagação do Eucalyptus spp.

As matrizes fornecedoras de propágulos são mantidas no próprio viveiro, o que proporciona maior eficiência das atividades de manejo quanto à irrigaçáo, nutriçáo e ao controle de pragas e doenças, além de proporcionar maior qualidade, velocidade e percentual de enraizamento das miniestacas (XAvier et al., 2003).

MARINHo et al. (2009) verificaram que miniestacas de goiabeira 'Paluma', provenientes de mudas juvenis, proporcionaram $100 \%$ de enraizamento. A alta capacidade de enraizamento verificada, no trabalho citado, pode ter ocorrido em virtude da juvenilidade dos tecidos, pois, de acordo com Fachinello et al. (2005), a idade do tecido interfere na capacidade rizogênica das estacas. $\mathrm{O}$ emprego da técnica da miniestaquia em goiabeira, em cultivares em pleno estádio de produção, ainda não foi avaliado.

A 'Paluma' é a goiabeira com maior número de plantas distribuídas por todas as regiốes de cultivo, atendendo aos mercados de frutas frescas e à indústria, com boa capacidade de enraizamento de estacas herbáceas. Outras cultivares possuem melhores características para o mercado de frutas frescas, como é o caso da Pedro Sato, cultivar de casca rugosa mais difundida no Estado de São Paulo (Pereira e Nachtigal, 2009). A goiaba 'Cortibel 1' é uma seleção de população de plantas obtidas de polinização aberta de uma variedade não identificada, provavelmente de origem australiana (Costa e Costa, 2003). Segundo os mesmos autores, desta população foram selecionados genótipos superiores e essas seleçôes são consideradas variaçôes regionais do Estado do Espírito Santo, com importância comercial no Estado. Os frutos da 'Cortibel 1' são de ótima aceitabilidade para produção de doces em calda e goiabada cascão e tamanho e resistência desejáveis para comercialização in natura. Entretanto, essa cultivar possui baixa percentagem de produção de mudas por enraizamento de estacas herbáceas, entre 5\% e 8\%. A 'Cortibel 6', outra variação dentro do grupo, possui casca rugosa e potencial para o mercado de frutas frescas no Estado do Espírito Santo.

Dessa forma, o objetivo deste trabalho foi avaliar a viabilidade da miniestaquia para as cultivares Paluma,
Pedro Sato, Cortibel 1 e Cortibel 6, quanto à emissão de brotaçóes pelas minicepas após sucessivas coletas, à capacidade de enraizamento e sobrevivência das miniestacas em diferentes épocas, bem como o crescimento das mudas, após enraizamento das miniestacas.

\section{MATERIAL E MÉTODOS}

As mudas de goiabeira (Psidium guajava L.) das cultivares Paluma, Pedro Sato, Cortibel 1 e Cortibel 6 foram obtidas pelo método de estaquia herbácea, no viveiro comercial Frucafé Mudas e Plantas Ltda EPP, localizado no município de Linhares, no Estado do Espírito Santo.

As estacas foram colocadas para enraizar em sacolas de polietileno com dimensões de $12 \times 22 \mathrm{~cm}$, preenchidas com substrato comercial Holambra Substratos Ltda, à base de casca de pinus $(70 \%)$ + pó da casca de coco $(30 \%)$, em câmara de nebulização intermitente climatizada $\left(28^{\circ} \mathrm{C}\right.$ de temperatura e $95 \%$ de umidade), cobertas com plástico raiodifusor + sombrite interno de $50 \%$ e com micronebulizador Fogger de vazão de $7 \mathrm{~L} \mathrm{~h}^{-1}$ sob pressão de $4,0 \mathrm{kgf} \mathrm{cm}^{-2}$. $\mathrm{O}$ ambiente foi controlado por aspersóes programadas com duração de 15 segundos a cada intervalo de 10 minutos.

Os experimentos foram instalados no município de Campos dos Goytacazes, Região Norte do Estado do Rio de Janeiro, localizada nas coordenadas $21^{\circ} 45^{\prime} 14^{\prime \prime} \mathrm{S}$ e $41^{\circ} 19^{\prime} 26^{\prime}$ W. Segundo a classificação climática de Köppen, o clima da Região Norte Fluminense é classificado como Aw, isto é, clima tropical úmido, com verão chuvoso, inverno seco e temperatura do mês mais frio superior a $18^{\circ} \mathrm{C}$.

Os dados climáticos do local durante o período de condução dos experimentos são apresentados na figura 1.

\section{Experimento 1: Produção de brotações}

Aos 90 dias após o estaqueamento, as mudas produzidas por estaquia herbácea, foram transplantadas para vasos cônicos estriados (altura de $30 \mathrm{~cm}$ ) com volume de $3,8 \mathrm{dm}^{3}$, preenchidos com substrato Plantmax Hortaliças ${ }^{\oplus}$, previamente adubado com $3 \mathrm{~kg} \mathrm{~m}^{-3}$ de osmocote ${ }^{\oplus}$, formulaçáo

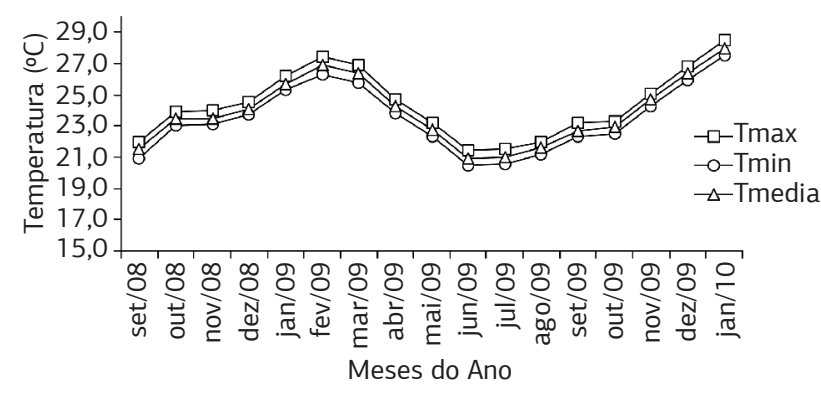

Figura 1. Médias mensais das temperaturas máxima, mínima e média em Campos dos Goytacazes (RJ), durante o período de manejo dos experimentos. 
de 22-4-8 + micronutrientes, $4 \mathrm{~kg} \mathrm{~m}^{-3}$ de superfosfato simples e $26 \mathrm{~kg} \mathrm{~m}^{-3}$ de calcário dolomítico (PRNT de $80 \%$ ) e mantidas em casa de vegetação.

O delineamento experimental utilizado foi o de blocos casualizados (DBC), com quatro tratamentos constituídos pelas cultivares, com quatro repetiçóes, sendo cada parcela composta por sete plantas.

Aos 47 dias após o transplantio (outubro de 2008), foi realizado o desponte da parte aérea das mudas, em tecido maduro a aproximadamente $11 \mathrm{~cm}$ do colo, formando-se assim as minicepas.

Após o desponte, as minicepas foram avaliadas quanto à produção de brotaçôes (contagem do número de brotaçốes emitidas, com no mínimo dois pares de folhas); comprimento e número de pares de folhas dessas brotaçōes; ao potencial de produção de miniestacas (PPM) e ao potencial de produção de miniestacas acumulada (PPMA) aos 49; 95; 130; 166; 229; 347 e 397 dias após o desponte. O PPM foi estimado pelo número total de pares de folhas totalmente expandidas da brotação, dividido pelo número mínimo de pares de folhas necessário para o preparo de uma miniestaca (com dois pares de folhas) e o PPMA foi estimado pela soma acumulada da produção potencial de miniestacas nas sete coletas.

Aos 95; 130; 166 e 347 dias após o desponte foi determinada a massa de matéria seca das brotaçóes emitidas. As médias foram submetidas a análises de variâncias e comparadas pelo teste de Tukey $(\mathrm{p}<0,05)$. As épocas de coletas de brotaçóes foram avaliadas em esquema de parcelas subdivididas no tempo e submetidas a análises de regressáo polinomial $(\mathrm{p}<0,05)$. Foram testados os modelos lineares e quadráticos e as equaçôes foram escolhidas de acordo com a significância e melhor ajuste $\left(\mathrm{R}^{2}\right)$.

\section{Experimento 2: Enraizamento e sobrevivência das miniestacas}

As brotaçôes coletadas nas minicepas aos 49, 229 e 397 dias foram utilizadas para avaliaçáo do enraizamento das miniestacas. As miniestacas foram preparadas com dois pares de folhas (independente do seu comprimento), dos quais o par de folhas basal foi retirado e o par de folhas apical teve o seu limbo reduzido à metade. As miniestacas foram colocadas para enraizar em tubetes de 280 $\mathrm{cm}^{3}$, preenchidos com substrato Plantmax Hortaliças. As miniestacas das cultivares Paluma, Pedro Sato, Cortibel 1 e Cortibel 6 tinham em média 5,50; 4,52; 4,17 e 4,28 cm de comprimento e diâmetro (medido na regiáo mediana do entrenó) de 2,76; 2,66; 2,55 e 2,78 $\mathrm{mm}$ respectivamente.

$\mathrm{O}$ experimento foi instalado em $\mathrm{DBC}$, em esquema fatorial $4 \times 3$, sendo constituído pelas quatro cultivares (Paluma, Pedro Sato, Cortibel 1 e Cortibel 6) e três épocas de estaqueamento (dezembro de 2008, e em junho e novembro de 2009), com quatro repetiçóes, sendo cada parcela constituída por seis miniestacas.

As miniestacas foram mantidas em câmara de nebulização com aspersôes programadas para irrigar durante 30 segundos a cada intervalo de 15 minutos, durante 62 dias.

Após esse período, foram avaliadas as seguintes variáveis: a porcentagem de enraizamento das miniestacas; o número de raízes adventícias primárias emitidas por miniestaca; o comprimento total e médio das raízes $(\mathrm{cm})$; a massa de matéria seca das raízes (mg) e a porcentagem de sobrevivência das miniestacas.

Os dados foram submetidos à análise de variância e as médias comparadas pelo teste de Tukey $(\mathrm{p}<0,05)$. As médias dos dados referentes ao sistema radicular das miniestacas (número, comprimento e massa de matéria seca) foram transformadas segundo a equação $(x+0,5)^{1 / 2}$.

\section{Experimento 3: Crescimento das mudas de goiabeira, obtidas após enraizamento das miniestacas}

As mudas cujo enraizamento foi finalizado em setembro de 2009 (coleta de miniestacas em junho de 2009) foram repicadas dos tubetes para sacolas de polietileno de $12 \times 22 \mathrm{~cm}$. Foi utilizado o substrato Plantmax Hortaliças ${ }^{\oplus}$, previamente adubado com $7 \mathrm{~kg} \mathrm{~m}^{-3}$ de superfosfato simples, $5,26 \mathrm{~kg} \mathrm{~m}^{-3}$ de uréia revestida e $26 \mathrm{~kg}$ $\mathrm{m}^{-3}$ de calcário.

$\mathrm{O}$ experimento foi instalado em $\mathrm{DBC}$, com quatro tratamentos constituídos pelas cultivares Paluma, Pedro Sato, Cortibel 1 e Cortibel 6, com quatro repetiçóes, sendo cada parcela constituída por seis mudas.

A altura das mudas foi avaliada aos 76 dias após a repicagem. Aos 83 dias após a repicagem seccionou-se a parte aérea das plantas rente ao colo e, em seguida, foi avaliado o número de folhas, a área foliar, a massa de matéria seca da parte aérea e das raízes (g). As médias foram submetidas a análises de variâncias e comparadas pelo teste de Tukey $(\mathrm{p}<0,05)$.

\section{RESULTADOS E DISCUSSÃO}

\section{Produção de brotações}

As minicepas de 'Paluma', 'Pedro Sato', 'Cortibel 1' e 'Cortibel 6' proporcionaram a mesma capacidade de emissão de brotações dentro de cada época de avaliação, exceto aos 397 dias após o desponte, quando foi verificado maior média de emissão de brotaçôes da cultivar Paluma em relaçáo à Cortibel 1 (Tabela 1). De 49 aos 166 dias após o desponte verificou-se aumento do número de brotaçôes emitidas pelas minicepas das quatro cultivares. Entretanto, aos 347 dias após o desponte, em todas as cultivares ocorreu redução no número de brotaçôes emitidas 
em relação aos 166 dias após desponte (Tabela 1). A produção de brotaçôes por minicepas em minijardins clonais vem sendo estudada em várias espécies. Em minicepas oriundas de seedlings de goiabeira 'Paluma', manejadas em tubetes de $50 \mathrm{~cm}^{3}$, Marinho et al. (2009) obtiveram na primeira coleta de brotação, realizada aos 39 dias após o desponte, 1,52 brotaçóes por minicepa. Em cedro australiano, Souza et al. (2009) obtiveram na primeira coleta, aos 70 dias após o desponte, 1,1 brotaçóes por minicepa.

A capacidade de rebrota das minicepas é essencial para viabilidade da produção de mudas por miniestaquia. $\mathrm{Na}$ propagação de eucalipto, a técnica da miniestaquia é utilizada com sucesso, com minicepas emitindo número médio de brotaçóes variando entre 1,7 e 11,9, dependendo do clone, da classe de tamanho das brotações e da época de avaliação (Titon et al., 2003). Cunha et al. (2008) relataram que a produçáo de brotos por minicepas de clones de eucalipto, manejadas no minijardim clonal em leito de areia e em tubetes, foi de 7,6 e 2,4 respectivamente. No presente trabalho, observa-se que o número de brotaçóes emitidas pelas minicepas variou de 0,67 a 4,96, entre as diferentes cultivares de goiabeira, e em diferentes intervalos de avaliação. Em função das diferentes características entre as culturas da goiabeira e do eucalipto (principalmente em relação à demanda por mudas), o número de brotaçóes, verificado neste trabalho, indica potencial adequado de rebrota para a propagação dessa espécie por miniestaquia.

É oportuno salientar que as médias do número de brotaçôes emitidas pelas minicepas avaliadas neste trabalho podem ser superiores, haja vista que os dados apresentados na tabela 1, referem-se apenas á contagem das brotaçôes quando havia no mínimo dois pares de folhas, consideradas aptas ao estaqueamento.

O maior intervalo de coleta de brotaçóes ocorreu entre 229 (maio de 2009) e 347 dias após o desponte (setembro de 2009). A menor emissão de brotação pelas minicepas verificada nesse intervalo pode estar associada às temperaturas mais baixas registradas nesse período, conforme pode ser verificado na figura 1 .

De modo geral, o comprimento e o número de pares de folhas das brotações emitidas pelas minicepas não diferiram entre as cultivares Paluma, Pedro Sato, Cortibel 1 e Cortibel 6 (Tabelas 1 e 2). Entretanto, em determinadas épocas, as cultivares Paluma e Pedro Sato tiveram

Tabela 1. Número e comprimento das brotações emitidas pelas minicepas de cultivares de goiabeira (Psidium guajava), em sete épocas de coleta de brotaçóes

\begin{tabular}{|c|c|c|c|c|c|c|c|c|}
\hline \multirow{3}{*}{ DAD } & \multicolumn{4}{|c|}{ Número de brotações } & \multicolumn{4}{|c|}{ Comprimento das brotações $(\mathrm{cm})$} \\
\hline & \multicolumn{4}{|c|}{ Cultivares } & \multicolumn{4}{|c|}{ Cultivares } \\
\hline & $\mathbf{P}$ & PS & C1 & C6 & $\mathbf{P}$ & PS & C1 & C6 \\
\hline 49 & 1,74 a C & 1,60 a $D$ & 0,78 a C & 1,89 a C & 30,52 a $A$ & 22,65 a $A$ & 9,86 b CDE & $20,55 a b$ A \\
\hline 95 & 2,93 a B & 1,92 a $D$ & 1,61 a $B C$ & 2,03 a $B C$ & 17,71 a $C D$ & 12,41 a $B C$ & 22,90 a $A$ & 17,06 a $A B$ \\
\hline 130 & 3,28 a $B$ & 2,64 a $C D$ & 2,14 a $A B$ & 3,07 a $A B$ & 18,42 a CD & 22,89 a $A$ & 13,56 a $B C D$ & 14,64 a $A B$ \\
\hline 166 & 4,85 a $A$ & 4,07 a $A B$ & 2,85 a $A$ & 4,07 a $A$ & 15,00 a D & 10,48 a C & 8,56 a $\mathrm{DE}$ & 10,35 a $B$ \\
\hline 229 & 3,64 a B & 3,24 a BC & 2,25 a $A B$ & 3,07 a $A B$ & 23,57 a $A B C$ & 15,96 a $A B C$ & 17,73 a $A B$ & 15,85 a $A B$ \\
\hline 347 & 2,85 a B & 2,14 a D & 0,67 a $C$ & 2,03 a BC & 26,07 a $A B$ & 18,97a AB & $6,10 \mathrm{~b} \mathrm{E}$ & $16,56 \mathrm{ab} A B$ \\
\hline 397 & 4,96 a $A$ & 4,39 ab $A$ & 2,35 b $A B$ & $3,43 a b A$ & 21,79 a BCD & 18,80 a $A B$ & 16,46 a $A B C$ & 17,97 a A \\
\hline CV $(\%)^{*}$ & \multicolumn{4}{|c|}{12,8} & \multicolumn{4}{|c|}{7,8} \\
\hline CV $(\%)^{* *}$ & \multicolumn{4}{|c|}{17,9} & \multicolumn{4}{|c|}{19,1} \\
\hline
\end{tabular}

Cultivares: $\mathrm{P}=$ Paluma; $\mathrm{PS}=$ Pedro Sato; $\mathrm{C} 1=$ Cortibel 1; C6= Cortibel 6. DAD = dias após o desponte. Médias seguidas pelas mesmas letras minúsculas na linha e mesmas letras maiúsculas na coluna, não diferem entre si pelo teste de Tukey $(\mathrm{p}<0,05)$.

$\mathrm{CV}(\%)^{*}=$ Coeficiente de variação da parcela e CV $(\%)^{* *}=$ Coeficiente de variação da subparcela.

Tabela 2. Número de pares de folhas das brotaçôes e potencial de produção de miniestacas das minicepas de cultivares de goiabeira (Psidium guajava), em sete épocas de coleta de brotaçóes

\begin{tabular}{|c|c|c|c|c|c|c|c|c|}
\hline \multirow{3}{*}{ DAD } & \multicolumn{4}{|c|}{ Número de pares de folhas das brotações } & \multicolumn{4}{|c|}{ Potencial de produção de miniestaca por minicepa } \\
\hline & \multicolumn{4}{|c|}{ Cultivares } & \multicolumn{4}{|c|}{ Cultivares } \\
\hline & $\mathbf{P}$ & PS & C1 & C6 & $\mathbf{P}$ & PS & C1 & C6 \\
\hline 49 & 5,57 a $A B C$ & $4,41 a b C D$ & 1,96 b DE & $3,95 a b B$ & 4,80 a $D$ & 3,48 a CD & 1,37 a $C$ & 3,71 a D \\
\hline 95 & 4,04 a C & 3,03 a $\mathrm{D}$ & 4,61 a $A B C$ & 3,72 a $B$ & 5,25 a $\mathrm{D}$ & 3,23 a $\mathrm{D}$ & 3,50 a $B C$ & 4,03 a $D$ \\
\hline 130 & 5,14 a $A B C$ & 6,14 a $A B$ & 4,21 a BC & 4,54 a B & 7,91 a C & 7,10 a $B$ & 4,32 a $B$ & 6,32 a $B C$ \\
\hline 166 & 4,36 a $B C$ & 3,96 a CD & 3,43 a $C D$ & 3,97 a $B$ & 10,05 a B & 7,24 a B & 4,98 a B & 7,48 a B \\
\hline 229 & 5,72 a $A B$ & 4,59 a $B C D$ & 5,33 a $A B$ & 4,73 a $B$ & 9,53 a BC & 7,26 a B & 5,23 a $B$ & 6,60 a $B C$ \\
\hline 347 & 5,89 a $A B$ & 4,84 a $A B C$ & 1,85 b $\mathrm{E}$ & 4,93 a $A B$ & 8,09 a $B C$ & 5,41 ab BC & 1,80 b C & $5,00 a b C D$ \\
\hline 397 & 6,56 a $A$ & 6,38 a $A$ & 5,84 a $A$ & 6,37 a $A$ & 15,35 a $A$ & 13,46 ab A & 7,71 b A & 10,55 ab A \\
\hline CV $(\%)^{*}$ & \multicolumn{4}{|c|}{5,8} & \multicolumn{4}{|c|}{14,9} \\
\hline CV $(\%)^{* *}$ & \multicolumn{4}{|c|}{15,6} & \multicolumn{4}{|c|}{15,4} \\
\hline
\end{tabular}

Cultivares: P= Paluma; PS= Pedro Sato; $\mathrm{C} 1=$ Cortibel 1; C6= Cortibel 6. DAD = dias após o desponte. Médias seguidas pelas mesmas letras minúsculas na linha e mesmas letras maiúsculas na coluna, não diferem entre si pelo teste de Tukey $(\mathrm{p}<0,05)$.

$\mathrm{CV}(\%)^{*}=$ Coeficiente de variaçăo da parcela e CV $(\%)^{* *}=$ Coeficiente de variaçăo da subparcela. 
os maiores comprimentos e os maiores números de pares folhas de brotaçôes em relação à cultivar Cortibel 1 .

As minicepas das cultivares Paluma, Pedro Sato, Cortibel 1 e Cortibel 6 tiveram o mesmo potencial de produção de miniestacas, dentro de cada época de avaliação, até os 229 dias após o desponte. Aos 347 e 397 dias após o desponte, a cultivar Paluma foi superior à cultivar Cortibel 1 para essa característica. Na última época de avaliação, verificou-se o maior potencial de produção de miniestacas para todas as cultivares. Quando se analisa o potencial de produção de miniestacas nas sete épocas de avaliação, observa-se superioridade desta característica na coleta 7 em relação às demais coletas (Tabela 2). Esses resultados diferem dos verificados por Wenduing et al. (2000), que observaram superioridade da produção de miniestacas por minicepas de Eucalyptus spp. na primeira coleta em relação às demais. A produção média de miniestaca/minicepa/coleta verificada por esses autores foi entre 1,5 e 2,3.

O potencial de produção de miniestacas por minicepas em minijardim clonal têm sido avaliado por diversos autores e para diversas espécies. Em Eucalyptus grandis, Titon et al. (2003) constataram que a produção de miniestacas variou entre clones e entre coletas, de modo que, em algumas coletas ocorreu decréscimo da produção de miniestacas e em outras, houve maior produção. A produçáo média mensal avaliada por esses autores foi de 9,7 miniestacas por minicepa. Em Eucalyptus benthamii, CunHA et al. (2005) verificaram menor produçáo de miniestacas pelas minicepas, na primeira coleta de brotaçáo. Os autores relataram que a produção de miniestacas aumentou após as sucessivas coletas. Em cedro-rosa, Xavier et al. (2003) verificaram menor produção de miniestacas na primeira coleta, quando comparadas às coletas posteriores. A produtividade média de miniestaca por minicepa por coleta verificada por esses autores foi de 1,3. Em ervamate, Wenduing et al. (2007) constataram aumento da produtividade de miniestacas por minicepa da primeira até a quarta coleta (com exceção da coleta 3 ), com posterior queda nas coletas 5, 6 e 7 e, por fim, novo aumento até as coletas 10 e 11 . A produçấo média de miniestacas por minicepa foi de 4,4 a cada 39 dias.

O potencial de produção de miniestacas acumulada, ao longo das sete coletas, para as cultivares Paluma, Pedro Sato, Cortibel 1 e Cortibel 6 é apresentado na figura 2 . A quantidade de miniestacas produzidas por minicepa indica o potencial de fornecimento de propágulos para a produção de mudas, que nesse experimento situou-se entre 57, 44, 27 e 41 miniestacas por minicepas, respectivamente, das cultivares Paluma, Pedro Sato, Cortibel 1 e Cortibel 6, aos 397 dias após o desponte. O número de minicepas a ser cultivado dependerá da demanda de mudas e da capacidade de enraizamento das miniestacas de cada cultivar. As cultivares Paluma, Pedro Sato, Cortibel 1 e Cortibel 6 tiveram o mesmo comportamento quanto à produção de massa de matéria seca das brotaçôes aos
95, 130, 166 e 347 dias após o desponte (Figura 3). A massa de matéria seca das brotaçóes nas quatro coletas é um indicador da qualidade das minicepas e do potencial de manutençáo da produçáo de fotoassimilados, mesmo em um sistema de podas contínuas e coletas sistemáticas das brotaçōes. As minicepas das goiabeiras adaptam-se ao confinamento do sistema radicular em vasos e sobrevivem e produzem em período de, pelo menos, 397 dias após o desponte, nas condiçóes desse experimento.

\section{Enraizamento e sobrevivência das miniestacas}

Com as cultivares Paluma, Pedro Sato, Cortibel 1 e Cortibel 6 não houve diferença quanto à capacidade de enraizamento na primeira época de coleta de miniestacas (dezembro). Na segunda época (junho), verificou-se com a cultivar Cortibel 1 menor porcentagem de enraizamento em relação à 'Paluma'; na terceira época (novembro), essa cultivar também proporcionou menor enraizamento em relação a 'Paluma', 'Pedro Sato' e 'Cortibel 6' (Tabela 3).

$\mathrm{Na}$ época de coleta, em dezembro, o efeito foi significativo na capacidade de enraizamento das miniestacas apenas para a cultivar Cortibel 1, com a maior porcentagem de enraizamento em relaçáo a novembro (Tabela 3). O menor percentual de enraizamento das miniestacas da 'Cortibel 1' verificado em novembro pode ter

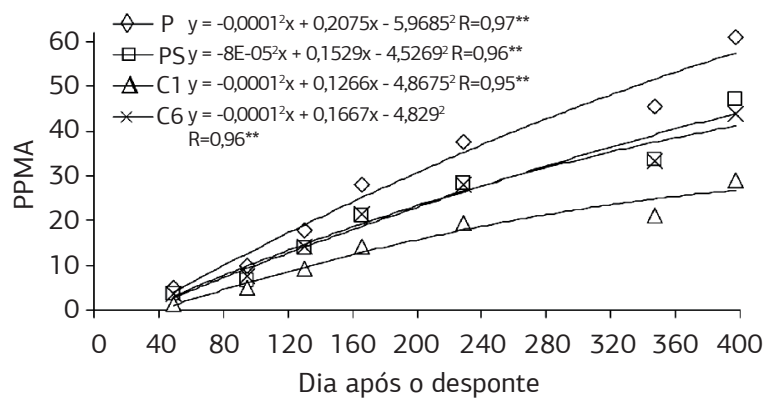

Figura 2. Potencial de produção de miniestacas acumulado (PPMA), por minicepa, das cultivares Paluma (P), Pedro Sato (PS), Cortibel 1 (C1) e Cortibel 6 (C6) observado no minijardim clonal.

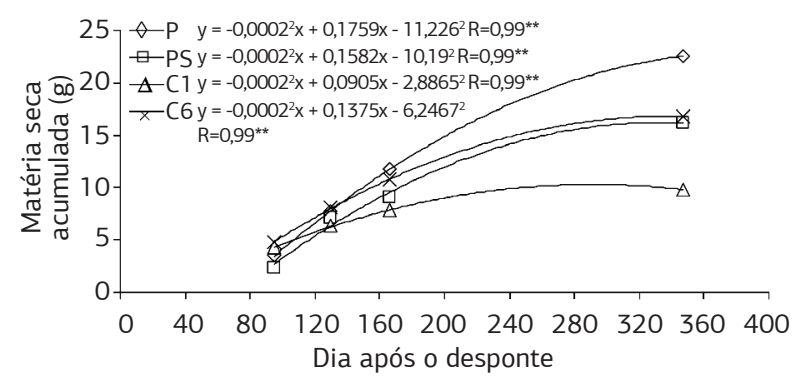

Figura 3. Média por minicepa da matéria seca acumulada das cultivares Paluma (P), Pedro Sato (PS), Cortibel 1 (C1) e Cortibel 6 (C6) observada em minijardim clonal. 
ocorrido devido à presença de botóes florais e flores nas brotaçóes emitidas pelas minicepas nessa época. Segundo FaChinello et al. (2005), estacas com gemas floríferas tendem a enraizar menos do que aquelas provenientes de ramos vegetativos em fase de crescimento ativo, o que mostra antagonismo entre a floração e o enraizamento.

Costa e Costa (2003) relataram que a 'Cortibel 1' possui baixa capacidade de enraizamento de estacas herbáceas, em torno de $5 \%$ a $8 \%$, independentemente da dosagem de AIB utilizada. Segundo MendonçA et al. (2007), a 'Cortibel 1' possui firmeza de polpa superior à de outras cultivares de mesa, indicando maior vida de prateleira o que tem justificado a procura por suas mudas. A dificuldade de enraizamento constatada até o momento pode ser um dos fatores limitantes para o aumento das áreas de plantio, que se tem restringido ao litoral capixaba.

O enraizamento da 'Cortibel 1' verificado no presente trabalho chegou a $75 \%$ quando as miniestacas foram coletadas em dezembro, indicando que a miniestaquia pode ser utilizada como técnica mais efetiva de multiplicação dessa cultivar.

A cultivar Paluma possui melhor desempenho em relação às cultivares Pedro Sato e Cortibel 1 para número de raízes adventícias primárias emitidas pelas miniestacas e comprimento total de raízes. Nas cultivares Paluma, Pedro Sato e Cortibel 6 não houve diferenças no comprimento médio de suas raízes. Por outro lado, as menores médias do comprimento médio de raízes foi verificada para a cultivar Cortibel 1 (Tabelas 3 e 4). A maior massa de matéria seca do sistema radicular foi verificada para a cultivar Paluma (Tabela 5). Pereira et al. (1991) observaram superioridade da cultivar Paluma em relação à 'Rica' quanto à quantidade de raízes produzidas pelas estacas herbáceas.

A época de estaqueamento influenciou apenas nas características de número de raízes emitidas pelas miniestacas e pelo comprimento médio de raízes. As menores médias para essas duas características foram observadas na primavera/verão (novembro) e no inverno (junho) respectivamente (Tabelas 3 e 4). Em oposiçẫo aos resultados verificados neste trabalho, Alcantara et al. (2007) verificaram que o maior número de raízes por miniestaca em Pinus taeda, foi obtido no inverno, na primavera e no verão, e o maior comprimento médio das raízes, verificado no inverno e na primavera. Assim, essas características podem mudar de acordo com a espécie e dependem, também, das condiçôes de enraizamento.

Não foi constatada diferença quanto à sobrevivência das miniestacas de 'Paluma', 'Pedro Sato', 'Cortibel 1' e 'Cortibel 6' no fim de 62 dias (Tabela 5).

Com relação às épocas de estaqueamento, as maiores médias de sobrevivência das miniestacas ocorreram

Tabela 3. Enraizamento e número de raízes emitido pelas miniestacas em função das cultivares de goiabeira (Psidium guajava) e das épocas de coleta das miniestacas

\begin{tabular}{|c|c|c|c|c|c|c|c|c|}
\hline \multirow{3}{*}{ Cultivares } & \multicolumn{4}{|c|}{ Enraizamento (\%) } & \multicolumn{4}{|c|}{ Número de raízes } \\
\hline & \multicolumn{4}{|c|}{ Épocas } & \multicolumn{4}{|c|}{ Épocas } \\
\hline & Dezembro & Junho & Novembro & $\overline{\mathrm{X}}$ & Dezembro & Junho & Novembro & $\overline{\mathrm{X}}$ \\
\hline$P$ & $91,66 \mathrm{~A} \mathrm{a}$ & $87,50 \mathrm{~A} \mathrm{a}$ & $87,50 \mathrm{~A} \mathrm{a}$ & 88,88 & 4,66 & 4,16 & 2,85 & $3,89 \mathrm{~A}$ \\
\hline PS & $75,00 \mathrm{~A} \mathrm{a}$ & $75,00 \mathrm{AB}$ a & $83,33 \mathrm{~A} \mathrm{a}$ & 77,77 & 2,20 & 3,24 & 1,95 & $2,46 \mathrm{~B}$ \\
\hline $\mathrm{C} 1$ & $75,00 \mathrm{~A} \mathrm{a}$ & $45,83 \mathrm{~B}$ ab & $16,66 \mathrm{~B} \mathrm{~b}$ & 45,83 & 2,33 & 2,24 & 0,52 & $1,69 \mathrm{~B}$ \\
\hline $\mathrm{C} 6$ & $79,16 \mathrm{~A} \mathrm{a}$ & $75,00 \mathrm{AB}$ a & $70,82 \mathrm{~A} \mathrm{a}$ & 74,99 & 2,34 & 3,70 & 2,02 & $2,68 \mathrm{AB}$ \\
\hline$\overline{\mathrm{X}}$ & 80,20 & 70,83 & 64,57 & & $2,88 \mathrm{a}$ & $3,33 \mathrm{a}$ & $1,83 \mathrm{~b}$ & \\
\hline $\mathrm{CV}(\%)$ & \multicolumn{4}{|c|}{25,2} & \multicolumn{4}{|c|}{19,5} \\
\hline
\end{tabular}

Cultivares: $\mathrm{P}=$ Paluma; $\mathrm{PS}=$ Pedro Sato; $\mathrm{C} 1=$ Cortibel $1 ; \mathrm{C} 6=$ Cortibel 6 . Médias seguidas pelas mesmas letras minúsculas na linha e mesmas letras maiúsculas nas colunas năo diferem entre si pelo teste de Tukey $(\mathrm{p}<0,05)$.

Tabela 4. Comprimento total e comprimento médio de raízes em função das cultivares de goiabeira (Psidium guajava) e das épocas de coleta das miniestacas

\begin{tabular}{|c|c|c|c|c|c|c|c|c|}
\hline \multirow{3}{*}{ Cultivares } & \multicolumn{4}{|c|}{ Comprimento total das raízes $(\mathrm{cm})$} & \multicolumn{4}{|c|}{ Comprimento médio das raízes $(\mathrm{cm})$} \\
\hline & \multicolumn{4}{|c|}{ Épocas } & \multicolumn{4}{|c|}{ Épocas } \\
\hline & Dezembro & Junho & Novembro & $\overline{\mathrm{X}}$ & Dezembro & Junho & Novembro & $\bar{X}$ \\
\hline$P$ & 43,00 & 27,66 & 31,06 & $33,90 \mathrm{~A}$ & 9,55 & 6,63 & 11,15 & $9,11 \mathrm{~A}$ \\
\hline PS & 16,32 & 19,35 & 19,04 & $18,23 \mathrm{BC}$ & 7,62 & 4,65 & 8,35 & $6,87 \mathrm{~A}$ \\
\hline $\mathrm{C} 1$ & 19,12 & 13,78 & 5,72 & $12,87 \mathrm{C}$ & 5,96 & 2,89 & 2,45 & $3,76 \mathrm{~B}$ \\
\hline C6 & 19,27 & 28,75 & 21,77 & $23,26 \mathrm{AB}$ & 7,29 & 5,64 & 8,89 & $7,27 \mathrm{~A}$ \\
\hline$\overline{\mathrm{X}}$ & $24,42 \mathrm{a}$ & $22,38 \mathrm{a}$ & 19,39 a & & $7,60 \mathrm{a}$ & $4,95 \mathrm{~b}$ & $7,71 \mathrm{a}$ & \\
\hline CV(\%) & \multicolumn{4}{|c|}{25,0} & \multicolumn{4}{|c|}{20,6} \\
\hline
\end{tabular}

Cultivares: $\mathrm{P}=$ Paluma; $\mathrm{PS}=$ Pedro Sato; $\mathrm{C} 1=$ Cortibel 1; $\mathrm{C} 6=$ Cortibel 6. Médias seguidas pelas mesmas letras minúsculas na linha e mesmas letras maiúsculas nas colunas não diferem entre si pelo teste de Tukey $(\mathrm{p}<0,05)$. 
no inverno (junho) e as menores no veráo (dezembro) (Tabela 5). As médias de temperaturas máximas observadas no período do verão, foram de 24,$5 ; 26,2$ e $27,4^{\circ} \mathrm{C}$. Temperaturas acima de $36^{\circ} \mathrm{C}$ foram observadas nesse período no interior da câmara de nebulização, o que pode ter prejudicado as miniestacas em relação ao período de inverno, cujas médias das temperaturas máximas foram de 21,$4 ; 21,5$ e $22{ }^{\circ} \mathrm{C}$. As miniestacas são herbáceas e muito sensíveis à desidratação que pode ser maior em temperaturas mais elevadas. BRONDANI et al. (2010) verificaram, também, que durante a primavera e o verão, em que foram registrados os maiores valores das temperaturas máximas, médias e mínimas, ocorreram os menores valores para a sobrevivência de miniestacas de Eucalyptus; no outono e inverno, nos quais existiu um decréscimo dos valores das temperaturas, observaram-se os maiores valores de sobrevivência dos clones.

\section{Crescimento das mudas de goiabeira, obtidas após enraizamento das miniestacas}

Foi verificado maior crescimento das mudas de 'Paluma' em altura, número de folhas, área foliar, massa de matéria seca da parte aérea e do sistema radicular em relaçáo às cultivares Pedro Sato, Cortibel 1 e Cortibel 6 (Tabela 6).

Segundo Costa e Costa (2003), o tempo de formação da muda por estaquia herbácea é de seis meses, desde a estaquia até o momento de serem levadas para o campo, quando as mudas atingem altura média entre 45 e $50 \mathrm{~cm}$ e oito pares de folhas.
Nas condições deste trabalho, as mudas de 'Paluma' e 'Pedro Sato', produzidas por miniestaquia, estavam com altura e número de pares de folhas suficientes para o plantio no campo, em menos de cinco meses. Nessa mesma época, foi constatado que a altura das mudas de 'Cortibel 1' e 'Cortibel 6' estava dentro dos padróes recomendados por Costa e Costa (2003) para o plantio das mudas no campo, entre 45 e $50 \mathrm{~cm}$ de altura.

Em trabalhos de estaquia herbácea de goiabeira 'Paluma', sem a utilizaçáo de reguladores de crescimento, Prado et al. (2003) observaram que aos 195 dias após o estaqueamento as mudas estavam com $70,65 \mathrm{~cm}$ de altura; $1044,4 \mathrm{~cm}^{2}$ de área foliar; 29,24 folhas; massa de matéria seca do sistema radicular e da parte aérea de 3,853 e 11,83 g respectivamente. Franco e Prado (2006) verificaram que aos 180 dias após o estaqueamento, as mudas tinham $42,5 \mathrm{~cm}$ de altura; 22 folhas; $3720 \mathrm{~cm}^{2}$ de área foliar; 9,23 $\mathrm{g}$ de massa de matéria seca do sistema radicular e $35,85 \mathrm{~g}$ de massa de matéria seca da parte aérea. Aos 210 dias após o estaqueamento, Franco et al. (2008) observaram que a massa de matéria seca do sistema radicular e da parte aérea foram de 3,09 e 20,54 g respectivamente.

Em síntese, a miniestaquia da goiabeira possui algumas vantagens como redução da área necessária para a formação do minijardim clonal; reduçáo dos custos de transporte e coleta das brotaçóes, pelo fato de matrizes serem mantidas no próprio viveiro; maior facilidade no manejo e controle de pragas e doenças; maior eficiência das atividades de manejo no minijardim clonal quanto à irrigação e nutrição das minicepas, além de reduzir o tempo de produçáo da muda.

Tabela 5. Matéria seca de raízes e sobrevivência das miniestacas em função das cultivares de goiabeira (Psidium guajava) e das épocas de coleta das miniestacas

\begin{tabular}{|c|c|c|c|c|c|c|c|c|}
\hline \multirow{3}{*}{ Cultivares } & \multicolumn{4}{|c|}{ Matéria seca das raízes (mg) } & \multicolumn{4}{|c|}{ Sobrevivência (\%) } \\
\hline & \multicolumn{4}{|c|}{ Épocas } & \multicolumn{4}{|c|}{ Épocas } \\
\hline & Dezembro & Junho & Novembro & $\overline{\mathrm{X}}$ & Dezembro & Junho & Novembro & $\overline{\mathrm{X}}$ \\
\hline$P$ & 72,50 & 80,85 & 110,25 & $87,86 \mathrm{~A}$ & 100,00 & 100,00 & 95,83 & $98,61 \mathrm{~A}$ \\
\hline PS & 37,75 & 39,50 & 48,80 & $42,00 \mathrm{~B}$ & 83,33 & 95,83 & 100,00 & $93,05 \mathrm{~A}$ \\
\hline $\mathrm{C} 1$ & 48,35 & 29,00 & 11,67 & 29,67 B & 87,50 & 100,00 & 87,49 & $91,66 \mathrm{~A}$ \\
\hline C6 & 55,52 & 56,60 & 54,92 & $55,68 \mathrm{~B}$ & 91,66 & 100,00 & 91,66 & $94,44 \mathrm{~A}$ \\
\hline$\overline{\mathrm{X}}$ & $53,53 \mathrm{a}$ & 51,48 a & $56,41 \mathrm{a}$ & & 90,62 b & $98,95 \mathrm{a}$ & $93,74 \mathrm{ab}$ & \\
\hline $\mathrm{CV}(\%)$ & \multicolumn{4}{|c|}{2,3} & \multicolumn{4}{|c|}{8,7} \\
\hline
\end{tabular}

Cultivares: $\mathrm{P}=$ Paluma; $\mathrm{PS}=$ Pedro Sato; $\mathrm{C} 1=$ Cortibel 1; $\mathrm{C} 6=$ Cortibel 6 . Médias seguidas pelas mesmas letras minúsculas na linha e mesmas letras maiúsculas nas colunas não diferem entre si pelo teste de Tukey $(\mathrm{p}<0,05)$.

Tabela 6. Altura, número de folhas, área foliar, matéria seca da parte aérea e das raízes das mudas, oriundas de miniestaquia das cultivares Paluma (P), Pedro Sato (PS), Cortibel 1 (C1) e Cortibel 6 (C6) aos 145 dias após o estaqueamento

\begin{tabular}{lccccc} 
Cultivares & Altura $(\mathbf{c m})$ & Número de folhas & Área foliar $\left.\mathbf{( c m}^{2}\right)$ & $\begin{array}{c}\text { Matéria seca da } \\
\text { parte aérea }(\mathbf{g})\end{array}$ & $\begin{array}{c}\text { Matéria seca das } \\
\text { raízes }(\mathbf{g})\end{array}$ \\
\hline PS & $51,65 \mathrm{~b}$ & $23,54 \mathrm{~b}$ & $1316,32 \mathrm{~b}$ & $12,33 \mathrm{~b}$ & $1,36 \mathrm{~b}$ \\
C1 & $44,58 \mathrm{~b}$ & $22,29 \mathrm{~b}$ & $1148,44 \mathrm{~b}$ & $11,14 \mathrm{~b}$ & $1,53 \mathrm{~b}$ \\
\hline C6 & $44,20 \mathrm{~b}$ & $22,37 \mathrm{~b}$ & $1320,92 \mathrm{~b}$ & $12,93 \mathrm{~b}$ & $1,72 \mathrm{~b}$ \\
\hline CV $(\%)$ & 10,8 & 9,8 & 14,5 & 19,7 & 20,7
\end{tabular}

Médias seguidas pelas mesmas letras não diferem entre si pelo teste de Tukey $(\mathrm{p}<0,05)$. 


\section{CONCLUSÃO}

A técnica da miniestaquia é viável para produção de mudas das cultivares Paluma, Pedro Sato, Cortibel 1 e Cortibel 6, em função da capacidade de rebrota das minicepas; das elevadas porcentagens de sobrevivência e enraizamento das miniestacas e das mudas com crescimento dentro do prazo e dos padróes físicos adequados à produçáo de mudas de goiabeiras. A coleta de miniestacas de 'Paluma', 'Pedro Sato', 'Cortibel 1' e 'Cortibel 6' em dezembro (verão) proporciona maior enraizamento. Entretanto, o percentual de enraizamento das miniestacas da 'Cortibel 1' é mais influenciado pelas épocas de coleta, sendo registrados menores percentuais de enraizamento em junho e em novembro. A maior sobrevivência das miniestacas foi verificada em junho (99\%) para todas as cultivares.

\section{AGRADECIMENTOS}

Ao Conselho Nacional de Desenvolvimento Científico e Tecnológico $(\mathrm{CNPq})$ e à Fundação de Amparo à Pesquisa do Estado do Rio de Janeiro (FAPERJ) pelo apoio financeiro e à Coordenação de Aperfeiçoamento de Pessoal de Nível Superior (CAPES), pela concessão da bolsa.

\section{REFERÊNCIAS}

ALCANTARA, G.B.; RIBAS, L.L.F.; HIGA, A.R.; RIBAS, K.C.Z.; KOEHLER, H.S. Efeito da idade da muda e da estação do ano no enraizamento de miniestacas de Pinus taeda L. Revista Árvore, v.31, p.399-404, 2007.

ALFENAS, A.C.; ZAUZA, E.A.V.; MAFIA, R.G.; ASSIS, T.F. Clonagem e doenças do eucalipto. Viçosa: UFV, 2004. 442p.

ALMEIDA, E.J.; SOARES, P.L.M.; SILVA, A.R.; SANTOS, J.M. Novos registros sobre Meloidogyne mayaguensis no Brasil e estudo morfológico comparativo com $M$. incognita. Nematologia Brasileira, v.32, p.236-241, 2008.

BRONDANI, G.E.; WENDLING, I.; GROSSI, F.; DUTRA, L.F.; ARAUJO, M.A. Miniestaquia de Eucalyptus benthamii x Eucalyptus dunnii: (II) sobrevivência e enraizamento de miniestacas em funçáo das coletas e estações do ano. Ciência Florestal, v.20, p.453-465, 2010.

COSTA, A.F.S.; COSTA, A.N. Tecnologias para produção de goiaba. Vitória: Incaper, 2003. 341p.

CUNHA, A.C.M.C.M.; WENDLING, I.; SOUZA JÚNIOR, L. Produtividade e sobrevivência de minicepas de Eucalyptus benthamii Maiden et Cambage em sistema de hidroponia e em tubete. Ciência Florestal, v.15, p.307-310, 2005.

CUNHA, A.C.M.C.M.; PAIVA, H.N.; BARROS, N.F.; LEITE, H.G.; LEITE, F.P. Relação do estado nutricional de minicepas com o número de miniestacas de eucalipto. Scientia Forestalis, v.36, p.203-213, 2008.

FACHINELLO, J.C.; HOFFMANN, A.; NATCHIGAL, J.C. Propagação de plantas frutíferas. Brasília: Embrapa Informaçôes Tecnológicas, 2005. 221p.

FRANCO, C.F; PRADO, R.M. Uso de soluções nutritivas no desenvolvimento e no estado nutricional de mudas de goiabeira: macronutrientes. Acta Scientiarum Agronomy, v.28, p.199-205, 2006.

FRANCO, C.F.; PRADO, R.M.; BRAGHIROLLI, L.F.; ROZANE, D.E. Marcha de absorção dos micronutrientes para mudas de goiabeiras cultivares Paluma e Século XXI. Bragantia, v.67, p.83-90, 2008

INSTITUTO BRASILEIRO DE GEOGRAFIA E ESTATÍSTICA - IBGE. Produção Agrícola Municipal. 2009. Disponível em: $<$ http//www.sidra.ibge.gov.br>. Acesso em 2/2/2011.

MARINHO, C.S.; MILHEM, L.M.A.; ALTOÉ, J.A.; BARROSO, D.G.; POMMER, C.V. Propagação da goiabeira por miniestaquia. Revista Brasileira de Fruticultura, v.31, p.607-611, 2009.

MARQUES, A.S.A.; COELHO, M.V.S.; FERREIRA, M.A.S.V.; DAMASCENO, J.P.S.; MENDES, A.P.; VIEIRA, T.M. Seca dos ponteiros da goiabeira causada por Erwinia psidii: níveis de incidência e aspectos epidemiológicos. Revista Brasileira de Fruticultura, v.29, p.488-493, 2007.

MENDONÇA, R.D.; FERREIRA, K.S.; SOUZA, L.M.; MARINHO, C.S.; TEIXEIRA, S.L. Caracteristicas físicas e químicas de goiabas 'Cortibel 1' e 'Cortibel 4' armazenadas em condiçôes ambientais. Bragantia, v.66, p.685-692, 2007.

PEREIRA, F.M.; NACHTIGAL, J.C. Goiabeira. In: BRUCKNER, C.H. Melhoramento de fruteiras tropicais. Viçosa: UFV, 2002. p.267-289.

PEREIRA, F.M.; NACHTIGAL, J.C. Melhoramento genético da goiabeira. In: NATALE, W.; ROZANE, D.E.; SOUZA, H.A.; AMORIM, D.A. Cultura da goiaba do plantio à comercializaçáo. Jaboticabal: Fundunesp, 2009. v.2, p.371-398.

PEREIRA, F.M.; PETRECHEN, E.H.; BENINCASA, M.M.P.; BANZATTO, D.A. Efeito do ácido indol butírico no enraizamento de estacas herbáceas de goiabeira (Psidium guajava L.) das cultivares 'Rica' e 'Paluma', em câmara de nebulização. Científica, v.19, p.199-206, 1991.

PIEDADE NETO, A. Goiaba vermelha, fonte de riqueza à saúde, ao trabalho e às naçóes. In: ROZANE, D.E., ARAÚJO COUTO, F.A. Cultura da goiabeira: tecnologia e mercado. Viçosa: Empresa Júnior de Agronomia, 2003. p.39-52.

PRADO, R.M.; CORRÊA, M.C.; CINTRA, A.C.O.; NATALE, W. Resposta de mudas de goiabeira à aplicação de escória de siderurgia como corretivo de acidez do solo. Revista Brasileira de Fruticultura, v.25, p.160-163, 2003.

SOUZA, J.C.A.V.; BARROSO, D.G.; CARNEIRO, J.G.A.; TEIXEIRA, S.L.; BALBINOT, E. Propagação vegetativa de cedroaustraliano (Toona ciliata M. Roemer) por miniestaquia. Revista Árvore, v.25, 205-213, 2009. 
TITON, M.; XAVIER, A.; REIS, G.G.; OTONI, W.C. Eficiência das minicepas e microcepas na produção de propágulos de clones de Eucalyptus grandis. Revista Árvore, v.27, p. 619-625, 2003.

WENDLING, I.; XAVIER, A.; GOMES, J.M.; PIRES, I.E.; ANDRADE, H.B. Propagação clonal de híbridos de Eucalyptus spp. por miniestaquia. Revista Árvore, v.24, p.181-186, 2000.

WENDLING, I.; DUTRA, L.F.; GROSSI, F. Produção e sobrevivência de miniestacas e minicepas de erva-mate cultivadas em sistema semi-hidropônico. Pesquisa Agropecuária Brasileira, v.42, p.289-292, 2007

XAVIER, A.; SANTOS, G.A.; WENDLING, I.; OLIVEIRA, M.L. Propagação vegetativa de cedro-rosa por miniestaquia. Revista Árvore, v.27, p.139-143, 2003.

ZIETEMANN, C.; ROBERTO, S.R. Efeito de diferentes substratos e épocas de coleta no enraizamento de estacas herbáceas de goiabeira, cvs. Paluma e Século XXI. Revista Brasileira de Fruticultura, v.29, p.31-36, 2007. 